\title{
Policy Implications of Structural Violence and Syndemic Dynamics: A Lens for Addressing Latinx Immigrant Diabetes Health Disparities
}

\author{
Janet Page-Reeves ${ }^{1}\left[\right.$ [ Lidia Regino ${ }^{2} \cdot$ Terry Schleder $^{3}$
}

Accepted: 24 November 2021 / Published online: 25 February 2022

(c) The Author(s), under exclusive licence to Springer Science+Business Media, LLC, part of Springer Nature 2022

\begin{abstract}
Purpose of Review The purpose of this review is to explore using theoretical frameworks of structural violence and syndemics to understand Latinx health disparities with a focus on type 2 diabetes (T2D). We propose that combining these frameworks is a valuable approach for revealing complex root-cause dynamics and explaining the nuances of how and why health disparities exist. We discuss the importance of the relationship between T2D, fear, and stigma.

Recent Findings Immigration policy creates structural conditions that invite unauthorized immigration while simultaneously excluding undocumented immigrants from access to healthcare resources. Structural exclusion then breeds fear of immigration status disclosure and deportation and, in the highly politicized immigration context that has emerged over the past two decades, also assigns social sigma to immigration status. Undocumented immigrants lack access to healthcare and health insurance; they cannot afford state-of-the-art drugs, they tend to be socially isolated and lack social capital to navigate systems; they are financially limited by poverty and lack of resources, emotionally taxed by the experience of discrimination, humiliation, and language-related challenges; and they have a toxic immigration stress load in the form of multidimensional fear. Potential areas for policy change are identified.

Summary Type 2 diabetes (T2D) follows racial, ethnic, and class fault lines that reflect unequal social and structural dynamics. Latinx immigrants are at disproportionate risk and explaining immigrant T2D social geography requires a holistic lens.
\end{abstract}

Keywords Structural violence $\cdot$ Immigrants $\cdot$ Health disparities $\cdot$ Diabetes $\cdot$ Policy

\section{Latinx Diabetes Health Disparities}

Over 34 million people in the USA have type 2 diabetes (T2D) (10.5\% of the US population) and another 88 million (34.5\%) have pre-T2D [1]. But T2D is not an equitable

This article is part of the Topical Collection on Economics and Policy in Diabetes

Janet Page-Reeves

JPage-Reeves@salud.unm.edu

Lidia Regino

lregino@salud.unm.edu

1 Department of Family \& Community Medicine and Office for Community Health, University of New Mexico,

Albuquerque, NM, USA

2 Office for Community Health, University of New Mexico, Albuquerque, NM, USA

3 Albuquerque, NM, USA disease. T2D follows racial, ethnic, and class fault lines that reflect unequal social and structural dynamics $[2,3 \bullet \bullet, 4]$. The burden of the disease and its consequences have a disproportionate impact among Hispanics/Latinos (the Latinx population), the largest minority population in the USA [5]. An analysis of National Health and Nutrition Examination Survey (NHANES) data found that Latinx T2D prevalence (22.6\%) was twice as high as that for non-Hispanic Whites (11.3\%) and was higher than any other racial/ethnic group included in the study [5]. The Latinx T2D incidence rate $(12.5 \%)$ is similarly significantly higher than that for nonHispanic Whites (7.5\%), ${ }^{1}$ with individuals of Mexican heritage, the largest Latinx ethnic group in the USA, having an even higher rate of $14.4 \%$ [6]. And not only are Latinx adults $70 \%$ more likely than non-Hispanic Whites to be diagnosed with T2D [7], the incidence of Latinx T2D is increasing at a faster rate [7]. They, and they are more likely to develop

\footnotetext{
${ }^{1}$ https://www.diabetes.org/resources/statistics/statistics-about-diabetes
} 
T2D at a younger age [5]. Moreover, Latinx T2D patients are more likely to have comorbidities including CVD, diabetic retinopathy, chronic renal disease, and diabetic neuropathy [8], and to experience critical negative impacts from comorbidities such as higher rates of amputations, kidney failure, vision morbidities, and blindness [5] —and disturbingly, the Latinx T2D-related mortality rate is notably higher $[8,9]$ with Latinx T2D patients 1.3 times more likely to die of T2D-related causes than their White nonHispanic peers [5].

\section{Diabetes Health Disparities Among Latinx Immigrants}

When thinking about these Latinx T2D health disparities, it is important to consider the situation specific to Latinx immigrants. More than 40 million immigrants $(13.7 \%$ of the population) reside in the USA [7], and nearly a third of the US Latinx population is immigrants [10]. Roughly $25 \%$ ( 11.3 million) of all immigrants do not have legal immigration documents [11], and Latinx immigrants account for three-quarters of all immigrants without legal immigration status [10,11], with Mexico the leading country of origin for both authorized and unauthorized immigration $[10,11]$.

Reflecting the disproportionate impacts of T2D among the overall US Latinx population discussed above, Latinx immigrants are also at disproportionate risk, and T2D has been rated as the most significant health-related threat for Latinx immigrants [12]. While some Latinx immigrants arrive with better health than their USA-based counterparts, the advantage decreases in relation to the amount of time they live in the USA [13]. One study of healthcare utilization among Latinx immigrants with T2D found that undocumented immigrants experienced notably poorer $\mathrm{T} 2 \mathrm{D}$ outcomes than immigrants with documentation [14]. In a study conducted along the border, researchers found that 1-in-4 adults who tested positive for T2D (25.9\%) were undiagnosed, with Mexican immigrants more likely to have T2D, and that those who tested positive for T2D who did not previously have a diagnosis had extremely poor glycemic control. Similarly, but even more remarkable, in a study with Mexican immigrants that we conducted in Albuquerque, New Mexico [15], we found that out of 100 people tested, the prevalence for T2D or pre-T2D was 56\% (38\% of participants were in the pre-T2D range and an additional $18 \%$ had uncontrolled T2D). The finding of 56\% was extremely high, but even more concerning was that only 29 of those 56 people were aware of their T2D status (51.8\% diagnosed, $48.2 \%$ undiagnosed).

\section{Diabetes, Social Determinants of Health, and Structural Violence}

Explaining the T2D social geography in the Latinx immigrant community requires a holistic lens as many of the contributing factors are social, structural, and political. The social determinants of health $(\mathrm{SDoH})$ framework that emerged from the socio-ecological model in public health $[16,17]$ which has now become mainstream in the design of health research and considerations for health promotion programming has helped to expand our understanding of the extent to which health outcomes reflect dynamics outside of the realm of medical care. As such, SDoH thinking has significantly enhanced our ability to comprehend the nature of health disparities in a valuable way. However, too often, $\mathrm{SDoH}$ are framed in a way that fails to move beyond a onedimensional conceptualization of context. As we have previously argued, "the socio-ecological model acknowledges that individuals exist within a context of social determinants without [necessarily] investigating how those social determinants operate" $[15$, p. 16]. In relation to T2D and immigrant health, we proposed moving beyond merely locating people within a context. The health literature, including our work, has demonstrated that a structural violence theoretical framework can reveal complex root-cause dynamics that might not be apparent using other analytical approaches.

Structural violence is understood to occur when unjust social structures (including public policy) create differences in access to resources and lead to disparate health outcomes for different populations [15, 18]. Early conceptualizations of the relationship that structural violence has to health disparities and T2D arose out of inquiry identifying negative health impacts resulting from colonialized contexts, oppression, and the production of powerlessness. In 2008, Kurtz [19] discussed how impacts of colonization and structural inequalities in health care and social services for Aboriginal women in Australia "silence" women's voices in a form of structural violence that produces health disparities, including high rates of T2D and other chronic diseases. Similarly, in 2011, Maar and colleagues [20] showed that social and political marginalization are root causes of high rates of T2D among First Nations communities in Canada. In 2017, Jurriaan $^{2}$ used structural violence to understand T2D in case studies from the USA, Mexico, India, and the Pacific Islands where dynamics of large-scale, international agribusiness operate to disempower local, historically oppressed populations, and in 2019, Wilson and McLennan [21] found that the industrialization of the food systems in Caribbean and Pacific Island communities has produced a form of structural

\footnotetext{
2 Jurriaan, Bart (2015). Structural violence, diabetes and agrocolonialism. A case study of the United States, Mexico, India and the Pacific Islands. Masters Thesis. Instituto Interuniversitario de Desarollo Social y Paz. United Nations.
} 
violence that is then further reproduced in nutrition interventions to address chronic disease such as T2D. In 2020, Lynch [22] expanded these notions through identification of the myriad ways that social disadvantage and inequality operate to produce specific social patterning in the distribution and incidence of T2D. The T2D social landscape reflects unequal social position and power that result in differential vulnerability to disease. It has become clear that biomedical interventions to treat or prevent T2D must take into account these up-stream and more sophisticated social, political, and cultural dynamics.

\section{Understanding Diabetes Structural Violence and the Syndemics of Toxic Fear Among Latinx Immigrants}

In relation to T2D among Latinx immigrants, a structural violence approach has proven particularly useful for explaining the nuances of how and why health disparities exist. The most important contributor to our understanding of the complex nature of T2D health disparities in the Latinx immigrant community, and in relation to T2D in general, is Emily Mendenhall. In her groundbreaking anthropological work on the syndemics of T2D, including her signifi-

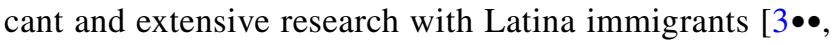
23-31], Mendenhall adds depth to the structural violence framing. Syndemics conceptualizes how multiple streams of influence-social, environmental, economic, and political-come together in a negative synergistic way to disproportionately impact the health of a particular group and produce health disparities. Mendenhall's syndemic approach disentangles the ways that T2D is a by-product of poverty and inequality that emerges through the synergistic interaction of context-specific factors that interplay with structural, emotional, and physical forms of violence. The resulting stress, social distress, and depression create unique social and physiological pathways for T2D that follow the existing social fault lines of oppression, historical trauma, and poverty.

The work of Mendenhall and that of other scholars explicitly utilizing a structural violence framework calls our attention to the importance of the relationship between $\mathrm{T} 2 \mathrm{D}$, fear, and stigma in immigrant communities. Larchanché [32] showed how structural violence is enacted in the lives of undocumented immigrants in France. Immigration policy creates structural conditions that invite unauthorized immigration while simultaneously excluding undocumented immigrants from access to healthcare resources. Structural exclusion then breeds fear of immigration status disclosure and deportation, and, in the highly politicized immigration context that has emerged over the past two decades in Europe, also assigns social sigma to immigration status. The intersection of these dynamics promotes health disparities among undocumented immigrants, regardless of their country of origin.

\section{Toxic Fear}

In 2013 [33], we pursued a similar approach to understand T2D health disparities among Mexican immigrants in Albuquerque, New Mexico. We used a structural violence framework to explore the nature of a ubiquitous fear that we unexpectedly identified to exist in qualitative data that we gathered. We conducted three two-session focus groups with a total of 18 people and six interviews with key community stakeholders. Focus group participants were Mexican immigrants with diabetes or family members/caregivers of people with diabetes. In reviewing the transcripts, we identified the theme of fear as a significant cross-cutting factor that affected how people approach their everyday lives. We found that exclusionary immigration policy and a highly politicized immigration context in the USA create three specific dimensions of fear that operate as risk factors for T2D by increasing stress:

1. Fear related to the cost of having T2D and being unable to pay given high rates of poverty and lack of access to healthcare-and inability to pay converges with a pervasive fear that third-party debt collection action will lead to disclosure of unauthorized immigration status

2. Fear related to language and discrimination-monolingual Spanish speakers fear not being able to communicate, and both monolingual speakers and those who speak English with a Spanish accent fear being discriminated against and humiliated because of their status as immigrants - and these language and discriminationrelated fears blend with the all-encompassing fear of being identified as an undocumented immigrant and being deported

3. Fear related to "cultural disconnect"-immigrant patients are humiliated and made to feel shame about their health beliefs or about the health practices they employ_ and again, this culturally based fear intersects with the fear of unwanted attention that could lead to a dangerous disclosure of immigration status

In 2019, Stutz and colleagues [34] further investigated how this generalized culture of fear creates toxic, chronic stress within undocumented Latinx immigrant communities in the USA, resulting in a wide range of detrimental 
health outcomes, including in relation to T2D. Horton and colleagues ${ }^{3}$ considering the dynamics of structural violence on the everyday lives of immigrants more broadly, implicate physical infrastructure and the built environment in relation to five key domains: transportation, spatial access to medical facilities, equitable law enforcement, equitable income, and insurance status and type. They demonstrate how social, legal, and economic barriers converge with spatial and infrastructural inequalities in the lives of undocumented Latinx immigrants in a Texas border community to create "infrastructural violence" in the allocation of resources and an arrangement of social space that perpetuates and reproduces inequality.

The syndemic synergy of fear, stress, and inequality produced by these structurally violent dynamics is not merely a philosophical concern, but has real, concrete, and cascading impact on the health of immigrants and their families, regardless of immigration status. In a study of data from the 2015 Latino National Health and Immigration Survey from 1493 Latinx children [35], researchers found that children from mixed-status families-where the children are US citizens (born in the USA) to immigrant parents without documents-had significantly poorer health. Among parents with a negative perception of their state's policy toward immigrants, there tended to be a higher fear of separation from their children if they sought medical care, and that those children tended to have even worse health outcomes. We know from recent history that separation of immigrant parents from children is not a fiction, but a real and present danger. Anecdotally, in 2016, while we were recruiting Latinx participants for a comparative effectiveness study on models of culturally appropriate T2D self-management [36] in the midst of the escalation of anti-immigrant public narrative and a deteriorating political climate in relation to immigration, we discovered that because of heightened fear, one woman who was experiencing symptoms of a heart attack and was told by her doctor that she needed to seek immediate treatment all but refused to go to the emergency room. Immigrant parents were not only canceling their own medical appointments all together, including T2D-related care, but they were also keeping children home from school. And we were incredibly disturbed by horrifying stories we gathered from the community. We heard of parents signing documents transferring legal custody of children to family members or friends with legal immigration status in case the parents were deported. We were told of parents who were providing children as young as kindergarteners with detailed

\footnotetext{
3 BS, S. N. H., Horton, S., Brett, J., Anthamatten, P., \& Hutson, S. (2017). Understanding social, legal, economic and spatial barriers to healthcare access in El Paso County, Texas Colonias an examination of structural violence using mixed methods. Masters Thesis, University of Colorado, Master of Arts Anthropology Program.
}

instructions about what to do "in case mommy and daddy don't show up to get you after school". Although subsequent to 2016, the political climate did improve, the underlying fear lingers, and it is not hyperbole to imagine the dramatic negative psychological and emotional impact that these experiences had on both parents and children. One of our project advisory board members described how her 8-yearold niece became so anxious that she had begun chewing her fingernails down to the quick.

\section{Toxic Fear and Gender}

In addition to thinking about the impact of structural violence on families, a number of studies focus on the unique experience of female immigrants with fear and trauma. In her 2012 book, Syndemic Suffering, Mendenhall [25] identified a syndemic interaction between violence, immigration stress, diabetes, depression, and abuse (VIDDA) common across the lives of her female Mexican immigrant participants who were patients in a public health diabetes clinic in Chicago. In 2019 [37], we refined our work on the impact of exclusionary immigration policy through a project that included exploring and understanding how dynamics of fear of "discovery" and deportation lead to and converge with social isolation, depression, and food insecurity among Mexican immigrant women, all of which are connected to increased risk for T2D. We reviewed transcript data from 20 interviews and 11 group sessions. Women shared experiences of social isolation, depression, food insecurity, fear of T2D, and the dangers and challenges associated with immigrant status. Participants described loneliness; domestic violence; rape; suicidal thoughts or attempted suicide; anger management problems; parenting challenges; interpersonal relationship dramas; physical, emotional, and financial abuse; chronic disease; legal and immigration-related threats to the health of their families; lack of self-confidence or low self-esteem; and poverty.

Similarly, in 2020, Meierotto, Castellano, and Curl [38] investigated how social isolation caused by fear of deportation synergistically produces multidimensional barriers to well-being among undocumented Latina farmworkers in Southwestern Idaho. Saleem and colleagues [39] described how structural violence operates in the lives of undocumented Latinas "who thought [life in the U.S.] would be different." They identified the importance of recognizing how gender, ethnicity, race, and immigration status intersect and are played out through direct and indirect violence and fear that characterize the female immigration experience. Not surprisingly given the social, cultural, and symbolic importance of food in the lives of Latinas [40], food insecurity is a primary source of struggle. Stanford [41] describes how the destructive dynamics of poverty and the politics of 
immigration policy come together in the operation of emergency food assistance programs where immigrant women in a border community in New Mexico come to get food for their families, creating both humiliating social interactions and unequal treatment. Carney [42] discusses immigrant women's strategies for surviving food insecurity in Santa Barbara, California, and how poverty and immigration status structure women's experience of food and the food environment. Food insecurity creates chronic stress and depression-risk factors for T2D-through what she calls a type of gendered suffering where the various fears associated with illegality are exacerbated by women's fear of being unable to fulfill the gendered responsibilities and social expectations of wife and mother.

\section{Metabolic Implications of Toxic Fear}

Structural violence has a specific direct impact on T2D health and healthcare. Mendenhall [27], Carney [43], and others discuss the metabolic implications of toxic immigration stressors. But immigrant T2D patients in our studies $[15,33,36,37]$ also postpone doctor visits or important tests to monitor blood sugar; they wait to buy their T2D medications or testing equipment until the end of the week, the month, or the next pay check-even if they are already running out—or, sometimes, they go without medicines in order to pay for food or other household expenses. Immigrant T2D patients who pay out-of-pocket for prescription medications because they lack insurance are not able to afford newer, more expensive options and instead must rely on inexpensive drugs such as metformin and glipizide, even if they prove individually less suitable, less effective, require more dosing, and have more side effects.

\section{Structural Violence, Diabetes Risk, and Public Policy}

Clearly, for undocumented Latinx immigrants, T2D risk is multidimensional. Undocumented immigrants lack access to healthcare and health insurance; they cannot afford state-ofthe-art drugs and quality health services, and safety-net providers who may have lower cost services are overwhelmed and often booked-out. In addition, undocumented immigrants tend to be socially isolated and lack social capital to navigate systems, financially limited by poverty and lack of resources and physically taxed from long hours of work at multiple low-wage jobs, food insecurity, and poor nutritional quality diet. They are also emotionally taxed by the experience of discrimination, humiliation, and languagerelated challenges and having to navigate culturally different or inappropriate social contexts. And, importantly, unauthorized immigrants have a toxic immigration stress load in the form of multidimensional fear as described above.

In obvious ways, these structurally violent and syndemic impacts have implications for public policy—specifically in relation to the need to improve access to health insurance and healthcare and create more paths to citizenship. In studies of healthcare utilization among Latinx immigrants with T2D [e.g., 14], the data suggest that high rates of uncontrolled T2D are directly related to a lack of health insurance-which means that undocumented immigrants commonly lack a primary care provider or regular healthcare facility. Similarly, in our study with Latinx immigrants in Albuquerque [15], the different dimensions of fear that we identified as stemming from structurally exclusionary immigration policies and resulting undocumented and uninsured statuses make it significantly less likely that undocumented immigrants will seek preventive care or treatment. The result is visible in the excessively high rates of undiagnosed and uncontrolled T2D that we found.

Relatedly, in a study of adaptive strategies to deal with the consequences of inadequate access to health care employed by undocumented Latinx immigrants, Patterson ${ }^{4}$ identified adjustments and improvisations used to fill the gaps and manage patients' T2D. Promotoras (e.g., Community Health Workers/CHWs) provide crucial information and access to resources, but rarely is their work fully funded-much of what they do is not recognized as work and therefore literally done for free, meaning that it is not truly valued or recognized by the health system, nor is it sustainable. In addition, providers and patients rely on alternative forms of care that are not standard-of-care treatments or not considered best-practice-but they may be the only options available. The resulting fragmentation of care makes it less likely that a T2D patient will be able to self-manage their condition and exacerbates suffering, disease progression, and complications.

\section{What Difference Does Policy Make?}

Undocumented immigrants can access some health care services at community health centers or private neighborhood clinics at a reduced cost or free of charge depending on their income, ${ }^{5}$ and under federal law, hospitals must provide emergency care, and Medicaid provides some supplemental

\footnotetext{
${ }^{4}$ Patterson, K. L. (2020). Filling in the gaps: adaptive strategies for latinx patients managing type 2 diabetes while lacking healthcare access. Masters Thesis, California State University, Long Beach, Department of Anthropology.

5 https://www.nilc.org/issues/health-care/update-on-access-to-healthcare-for-immigrants-and-their-families/
} 
funding. ${ }^{6}$ However, they are not eligible for Medicare, Medicaid, or the Child Health Insurance Program (CHIP), and they cannot purchase insurance through the Affordable Care Act (ACA) marketplaces. In a study of 50,000 immigrants in the USA from the Survey of Income and Program Participation (SIPP) [44], researchers found in relation to the number of health provider visits that states with more restrictive laws (such as Mississippi) have significantly fewer visits among undocumented adults. And related but not surprising, a review of 29 articles that focused on health disparities for immigrants living in the USA [43] found that although state immigration policy varied, immigrants residing in states with restrictive immigration laws had a higher prevalence of chronic illness.

Federal mandates dictate eligibility guidelines that restrict access for undocumented immigrants to federally funded resources, benefits, and programs, but states also have some discretion to modify policies [45••]. A number of policies make insurance more affordable and improve access to care. For example, since 2002, 16 states have opted to extend CHIP coverage to unborn children without consideration of the mother's immigration status. ${ }^{7}$ Six states (CA, IL, MA, NY, OR, and WA) and DC use state funds to cover income-eligible children regardless of immigration status, and California adopted expanded coverage for income-eligible undocumented immigrant young adults up to age $25 .^{8}$ Ten states and municipalities [45••] use public funds to cover insurance-type comprehensive coverage using the rhetoric of coverage for all local residents, with all being a euphemism for uninsured people, including undocumented immigrants. California, Massachusetts, and New York are also using local (county/city or state) funds to establish innovative pilot medical home programs for undocumented immigrants. ${ }^{9}$ In the Washington Health Benefit Exchange Sponsorship Program (Washington State), ${ }^{10}$ mixed-status families can apply for premium tax credits or lower out-of-pocket costs for private insurance for dependent family members who are eligible for coverage. Those who are not applying for health coverage for themselves are not asked if they have eligible

\footnotetext{
${ }^{6}$ https://www.kff.org/racial-equity-and-health-policy/issue-brief/ health-coverage-and-care-of-undocumented-immigrants/

7 https://www.kff.org/racial-equity-and-health-policy/issue-brief/ health-coverage-and-care-of-undocumented-immigrants/

8 https://www.kff.org/racial-equity-and-health-policy/issue-brief/ health-coverage-and-care-of-undocumented-immigrants/

${ }^{9}$ https://www.communitycatalyst.org/resources/publications/docum ent/Advocacy-Guide-ImmigrantsCoverage.pdf

${ }^{10}$ https://www.wahbexchange.org/new-customers/who-can-sign-up/ immigrants/
}

immigration status. And, various pieces of legislation ${ }^{11}$ that were passed in relation to the COVID-19 pandemic provided funds to health care providers that expanded the availability of free testing for COVID-19. States have flexibility to cover testing, treatment, and vaccines for COVID-19 as emergency Medicaid. US Citizenship and Immigration Services (USCIS) posted an alert clarifying that it will not consider COVID-19 testing, treatment, or preventive care to create a problem in relation to the public charge determination.

\section{A Case Study from New Mexico}

In New Mexico, the second poorest state [46], nearly 50\% of the population is Latinx (49.3\%) [47], and Latinx poverty is $21.3 \% .^{12}$ There are approximately 60,000 undocumented Latinx immigrants in New Mexico, ${ }^{13}$ and immigrants are known to experience poverty at an even higher rate. Given that individuals in New Mexico living in poverty are three times more likely to have diabetes than those making over $\$ 50,000$ a year [48], the diabetes risk for low-income, undocumented Latinx immigrants is disproportionately high and is recognized as a significant health threat in the immigrant community. This fact dovetails with broader efforts to improve access to healthcare for immigrants in New Mexico. For nearly 20 years, public health advocates pressured for comprehensive safety net or charity care programs to cover some or all of the cost of needed medical and preventive care for undocumented immigrants. A key element of this struggle was intensive advocacy on the part of public, nonprofit, academic, and community stakeholders and allies in Albuquerque/Bernalillo County (including co-authors Regino and Schleder). The primary objective was for the state's largest safety-net health system, a publicly funded non-profit hospital, to change a uniquely discriminatory policy that excluded undocumented immigrants from the hospital's publicly funded indigent and charity care program. Denying access to anyone without a Social Security number effectively made healthcare out of reach for undocumented immigrants.

\footnotetext{
11 https://www.nilc.org/issues/health-care/update-on-access-tohealth-care-for-immigrants-and-their-families/

12 Talk Poverty-New Mexico. Poverty stats for NM related to all people, whites, Latinos, women, and women headed HHs. https:// talkpoverty.org/state-year-report/new-mexico-2020-report/

13 Immigrants help drive New Mexico's economy. New Mexico Voices for children; https://www.nmvoices.org/archives/14197
} 
Through years of negotiations with the hospital and local political leadership, a Governor's Healthcare Summit, a public media campaign that framed access to healthcare as a basic human right, many lawsuits, community organizing, and a "listening tour" where those with primary impact could voice their concerns, many small reforms were achieved that benefitted low-income New Mexicans, including undocumented immigrants: improved access to language support services, a self-pay discount of $45 \%$ for uninsured/uninsurable patients, agreements to change debt collection for low-income debtors and institute payment plans, the expansion of primary care/family medicine clinics to four low-income neighborhoods, the creation of two lowcost primary care community clinics (Casa de Salud and One Hope Centro de Vida) with training opportunities for medical students and medical residents, and the formation of a CHW network located in community-based organizations and funded by the county. However, in the long run, a key factor influencing more dramatic policy change was the increasing awareness on the part of the public and policymakers that undocumented immigrants are also taxpayers, paying their share of personal, property, sales, and excise taxes even as they are ineligible for most public benefits. A report from New Mexico Voices for Children ${ }^{14}$ found that approximately 60,000 undocumented New Mexicans pay roughly $\$ 68$ million in annual state and local taxes.

In culmination of these numerous and intensive advocacy efforts and evolving policy arguments, in 2021, the state of New Mexico passed historic legislation prohibiting county indigent programs from discriminating against or denying health care to immigrants based on their immigration status. This legislation requires that the hospital amend its policies and provide coverage regardless of whether or not a patient has a Social Security number. The change is sure to positively impact the health and wellbeing of the immigrant community, with particular potential for improvements in T2D prevention, treatment, and self-management.

\section{Implications for Policy}

Potential for policy change to address immigrant health disparities has two dimensions — one is about expanding access to healthcare, and one is about a paradigm shift in the way that we think about health and healthcare from a perspective of human rights.

Areas for policy change that would expand access have been identified in a report by Community Catalyst, ${ }^{15}$ a

\footnotetext{
${ }^{14}$ Immigrants help drive New Mexico's Economy. New Mexico Voices for children; https://www.nmvoices.org/archives/14197

15 https://www.communitycatalyst.org/resources/publications/docum ent/Advocacy-Guide-ImmigrantsCoverage.pdf
}

national health advocacy organization that works on health equity issues:

- Require non-profit hospitals (like that in New Mexico) to make financial assistance programs available to undocumented immigrants. As per ACA requirement, nonprofit hospitals must work with community partners and develop strategies to meet community health needs and this sort of change is allowable.

- Allow undocumented immigrants to buy into stateadministered basic health plans (BHPS) created under the Affordable Care Act (ACA). Under the ACA, states have the option to create BHPSs to meet the health needs of community members less than $200 \%$ of the Federal Poverty Level and low-income legally documented immigrants. A state must create the infrastructure to leverage the federal funds, but after established, states can elect to cover the cost of subsidy to immigrants not eligible for federal funds.

- Allow undocumented immigrants to buy into Medicaid. States are allowed to create a Medicaid Buy-In Option without federal approval. The Buy-In Option would allow immigrants an opportunity to purchase insurance at a premium equivalent to that of other payees and, if possible, create a state-funded subsidy to allow low-income immigrants a sliding scale.

- Offer low-income, undocumented immigrants bronze-like plans to supplement existing emergency Medicaid benefits. States could use state funds to subsidize purchase of coverage in the individual market to supplement emergency Medicaid benefits for low-income undocumented immigrants to cover emergency hospitalization and labor/ delivery services. Those covered would still be responsible for deductibles and coinsurance which could be costly.

The need for a paradigm shift was highlighted in a study by Arega [45••] of vastly different health outcomes for undocumented immigrants in Indiana and Illinois that provides important insights into the relationship between the policy landscape and local politics and offers a roadmap for public health advocates. Arega did not find that policies granting access in the two states were particularly different, but rather attributed differential inter-state differential health outcomes to fundamentally different local rhetoric about immigrants, immigration, and healthcare-related deservingness. In Indiana, the public narrative assumes that undocumented immigrants do not deserve health care, and this message has been normalized in the community and internalized by immigrants themselves-so that they do not seek care. In Illinois, public discussions of undocumented immigrants and health care access use the language of healthcare as a basic human right. Larchanché [32], in some of the earliest work using a structural violence framework to understand health disparities among undocumented 
immigrants in France, called attention to the role of discourse in creating stigma through a narrative of undeservingness that negatively impacts patient health status (low self-esteem and psychological distress) while actively diminishing access to care and discursively reproducing negative immigrant stereotypes and promoting attitudes that moralize about illegitimacy. The key take-away from both Illinois and New Mexico, then, is that to achieve meaningful change, advocacy efforts related to health care access for undocumented immigrants must be rooted in this basic understanding - and by extension, the need for a national narrative shift to embrace healthcare as a human right. This type of shift aligns with the theoretical frameworks of structural violence and syndemics that provided a foundation for this review of T2D disparities among Latinx immigrants.

\section{In Conclusion}

This review examined the literature employing structural violence and syndemic theoretical frameworks for understanding health disparities on Latinx immigrant health disparities with a focus on T2D. Latinx immigrants are at disproportionate risk, and explaining immigrant T2D social geography requires a holistic lens. We proposed that combining these frameworks is a valuable approach for revealing complex root-cause dynamics and explaining the nuances of how and why health disparities exist. We discuss the importance of the relationship between T2D, fear, and stigma. We discuss how immigration policy creates structural conditions that invite unauthorized immigration while simultaneously excluding undocumented immigrants from access to healthcare resources. Structural exclusion then breeds fear of immigration status disclosure and deportation and, in the highly politicized immigration context that has emerged over the past two decades, also assigns social sigma to immigration status. Undocumented immigrants lack access to healthcare and health insurance; they cannot afford state-of-the-art drugs; they tend to be socially isolated and lack social capital to navigate systems; they are financially limited by poverty and lack of resources and emotionally taxed by the experience of discrimination, humiliation, and language-related challenges; and they have a toxic immigration stress load in the form of multidimensional fear. Potential areas for policy change are identified.

Availability of Data and Material Not applicable.

Code Availability Not applicable.

\section{Declarations}

Ethics Approval Not applicable.
Consent to Participate Not applicable.

Consent for Publication Not applicable.

Competing Interests The authors declare no competing interests.

\section{References}

Papers of particular interest, published recently, have been highlighted as: $\bullet$ Of major importance

1. Centers for Disease Control and Prevention (CDC). National Diabetes Statistics Report: 2020 estimates of diabetes and its burden in the United States. CDC \#CS314227-A. https://www. cdc.gov/diabetes/pdfs/data/statistics/national-diabetes-statisticsreport.pdf.

2. Gaskin DJ, Thorpe RJ Jr, McGinty EE, Bower K, Rohde C, Young JH, LaVeist TA, Dubay L. Disparities in diabetes: the nexus of race, poverty, and place. Am J Public Health. 2014;104(11):2147-55.

3. $\bullet$ Mendenhall E. Rethinking diabetes: entanglements with trauma, poverty, and HIV. Ithaca and London: Cornell University Press; 2019. ISBN 9781501738432. The most important and groundbreaking research on structural violence and diabetes is Mendenhall's extensive and masterful work on the syndemic dynamics of diabetes health disparities. Mendenhall's "complex and holistic analysis of diabetes offers timely insights for rethinking, disentangling, and making sense of the social and structural nexus undergirding diabetes health disparities". [5, p. 106].).

4. Page-Reeves J. Book review: rethinking diabetes: entanglements with trauma, poverty and HIV. In: Mendenhall E, editor. Cornell University Press. New York; 2019.

5. Velasco-Mondragon E, Jimenez A, Palladino-Davis AG, Davis D, Escamilla-Cejudo JA. Hispanic health in the USA: a scoping review of the literature. Pub Health Rev. 2016;37(1):1-27.

6. Avilés-Santa ML, Colón-Ramos U, Lindberg NM, Mattei J, Pasquel FJ, Pérez CM. From sea to shining sea and the great plains to Patagonia: a review on current knowledge of diabetes mellitus in Hispanics/Latinos in the US and Latin America. Front Endocrinol. 2017;10(8):298.

7. Office of Minority Health (OMH) U.S. Department of Health and Human Services (HHS). Diabetes and Hispanic Americans. https://minorityhealth.hhs.gov/omh/browse.aspx?lvl=4\&lvlid=63.

8. Centers for Disease Control and Prevention (CDC) Diabetes: Hispanic/Latino Americans and type 2 diabetes. https://www. cdc.gov/diabetes/library/features/hispanic-diabetes.html.

9. Calman NS, Hauser D, Schussler L, Crump C. A risk-based intervention approach to eliminate diabetes health disparities. Primary Health Care Res Dev. 2018;19(5):518-22.

10. Budiman A. Key Findings About US Immigrants. Pew Research Center; 2020. https://www.pewresearch.org/fact-tank/2020/08/ 20/key-findings-about-u-s-immigrants/.

11. Ornelas IJ, Yamanis TJ, Ruiz RA. The health of undocumented Latinx immigrants: what we know and future directions. Ann Rev Public Health. 2020;1(41):289-308.

12. Chaufan C, Davis M, Constantino S. The twin epidemics of poverty and diabetes: understanding diabetes disparities in a lowincome Latino and immigrant neighborhood. J Comm Health. 2011;36(6):1032-43. 
13. Engelman M, Ye LZ. The immigrant health differential in the context of racial and ethnic disparities: the case of diabetes. Imm Health. Imm Health: Emerald Publishing Limited; 2019.

14 Do EK, Matsuyama RK. Healthcare utilization among Hispanic immigrants with diabetes: investigating the effect of U.S. documentation status. J Immigr Minor Health. 2014;2:189-94.

15. Page-Reeves J, Mishra SI, Niforatos J, Regino L, Bulten R. An integrated approach to diabetes prevention: anthropology, public health, and community engagement. Qual R (Online). 2013;18:1.

16. Ogunwole SM, Golden SH. Social determinants of health and structural inequities - root causes of diabetes disparities. Diab Care. 2021;44(1):11-3.

17. Lucyk K, McLaren L. Taking stock of the social determinants of health: a scoping review. PloS one. 2017;12(5):e0177306.

18. Farmer P. Pathologies of power. University of California Press; 2004.

19. Kurtz DL, Nyberg JC, Van Den Tillaart S, Mills B. Silencing of voice: an act of structural violence urban Aboriginal women speak out about their experiences with health care. Int J Indig Health. 2008;4(1):53-63.

20. Maar AD, Manitowabi DG, McGregor L, Corbiere C. Serious complications for patients, care providers and policy makers: tackling the structural violence of First Nations people living with diabetes in Canada. Int Indig Pol J. 2011;2:6.

21. Wilson M, McLennan A. A comparative ethnography of nutrition interventions: structural violence and the industrialization of large-scale agri-food systems in the Caribbean and the Pacific. Soc Sci Med. 2019;228:172-80.

22. Lynch EB. Uncovering the mechanisms underlying the social patterning of diabetes. EClinMed. 2020;19.

23. Mendenhall E, Seligman RA, Fernandez A, Jacobs EA. Speaking through diabetes: rethinking the significance of lay discourses on diabetes. Med Anth Q. 2012;24(2):220-39.

24. Mendenhall E, Fernandez A, Adler N, Jacobs EA. Susto, coraje, and abuse: depression and beliefs about diabetes". Cult Med Psych. 2012;36(3):480-92.

25. Mendenhall E, Jacobs EA. Interpersonal abuse and depression among Mexican immigrant women with type 2 diabetes. Cult Med Psychol. 2012;6(1):136-53.

26. Mendenhall E. Syndemic suffering: social distress, depression, and diabetes among Mexican immigrant women. New York: Left Coast Press; 2012.

27. Mendenhall E. Beyond comorbidity: a critical perspective of syndemic depression and diabetes in cross-cultural contexts. Med Anth Q. 2016;30(4):462-78.

28. Mendenhall E. The "cost" of health care: poverty, depression, and diabetes among Mexican immigrants in the United States. In Global Mental Health. Routledge. 2016:205-220.

29. Mendenhall E, Kohrt BA, Norris SA, Ndetei D, Prabhakaran D. Non-communicable disease syndemics: poverty, depression, and diabetes among low-income populations. Lancet. 2017;389(10072):951-63.

30. Singer M, Ostrach B, Bulled N, Mendenhall E. Syndemics and a biosocial conception of health. Lancet. 2017;389:941-50.

31. Mendenhall E. Metabolic reflections: blurring the lines between trauma and diabetes". Am Anth. 2020;122(3):664-5.

32. Larchanché S. Intangible obstacles: health implications of stigmatization, structural violence, and fear among undocumented immigrants in France. Soc Sci Med. 2012;74(6):858-63.

33. Page-Reeves J, Niforatos J, Mishra S, Regino L, Gingrich A, Bulten R. Health disparity and structural violence: how fear undermines health among immigrants at risk for diabetes. Health Disp Res Prac. 2013;6(2):30-48.

34. Stutz M, Rivas-Lopez V, Lonquich B, Baig AA. Health repercussions of a culture of fear within undocumented immigrant communities. J Gen Intern Med. 2019;34(9):1903-5.
35. Vargas ED, Ybarra VD. U.S. citizen children of undocumented parents: the link between state immigration policy and the health of Latino children. J Imm Min Health. 2017;19(4):913-20.

36. Page-Reeves J, Regino L, Murray-Krezan C, Bleecker M, Erhardt E, Burge M, Bearer EL, Mishra S. A comparative effectiveness study of two models for culturally competent diabetes self-management programming for Latinos from low-income households. BMC Endo Dis: Protocol Section. 2017;17;46.https://doi.org/10. 1186/s12902-017-0192-4

37. Page-Reeves J, Shrum S, Rohan-Minjares F, Thiedeman T, Perez J, Murrietta A, ... Ronquillo F. Addressing syndemic health disparities among Latina immigrants using peer support. J Rac Eth Health Dis. 2019;2:380-392.

38. Meierotto L, Castellano RLS, Curl C. Isolation and fear of deportation: intersectional barriers to well-being among Latina farmworkers in Southwestern Idaho. Cult Agric Food Environ. 2020;2020(2):93-102.

39 Saleem R, Pagan-Ortiz ME, Morrill Z, Brodt M, Andrade L. "I thought it would be different": Experiences of structural violence in the lives of undocumented Latinas. Peace Conflict J Peace Psychol. 2020;2:171.

40. Page-Reeves J. Conceptualizing food insecurity and women's agency: a synthetic introduction. In: Page-Reeves J, editor. Women redefining the experience of food insecurity: life off the edge of the table. Lanham: Lexington Books of Rowman \& Littlefield; 2014. p. 3-44.

41. Stanford L. Negotiating food security along the U.S.-Mexican border: social strategies, practice, and networks among Mexican immigrant women. In: Page-Reeves J, editor. Women redefining the experience of food insecurity: life off the edge of the table. Lanham: Lexington Books of Rowman \& Littlefield; 2014. p. 105-26.

42. Carney M. 'La lucha diaria': migrant women in the fight for healthy food. In: Page-Reeves J, editor. Women redefining the experience of food insecurity: life off the edge of the table. Lanham: Lexington Books of Rowman \& Littlefield; 2014. p. 127-44.

43. Hall E, Cuellar NG. Immigrant health in the United States: a trajectory toward change. J Transcul Nurs. 2016;27(6):611-26.

44. Dondero M, Altman CE. Immigrant policies as health policies: state immigrant policy climates and health provider visits among US immigrants. SSM Pop Health. 2020;10:100559.

45.• Arega CA. Structural Violence, Politics and Notions of Healthcare Deservingness for Undocumented Latino Immigrants in Indiana vs. Illinois. Anthropo Undergr Res J. 2020;VI; https:// anthropology.nd.edu/undergraduate-program/anthrocentric/volume-vi/ . Arega documents the differences in health outcomes for undocumented immigrants in two states and shows how disparities are created as much by the framing of healthcare as something that must be deserved rather than as a human right. This is an important work because it demonstrates how politics and public narratives have a key impact on health outcomes.

46. U.S. Census Bureau. Selected Economic Characteristics, 2009-2013 American Community Survey 5-Year Estimates; http://factfinder. census.gov/bkmk/table/1.0/en/ACS/10_5YR/DP03/0400000US35.

47. United States Census Bureau - Quickfacts, New Mexico. Percentage of Whites and Latinos in New Mexico; https://www. census.gov/quickfacts/NM.

48. State Center for Health Statistics. New Mexico Selected Health Statistics Annual Report, 2012. Santa Fe: New Mexico Department of Health; 2012; http://nmhealth.org/data/view/vital/141/.

Publisher's Note Springer Nature remains neutral with regard to jurisdictional claims in published maps and institutional affiliations. 